\title{
Nikola tesla - o gênio da modernidade
}

\section{Nikola tesla - the genius of modernity}

DOI: 10.46814/lajdv3n1-027

Recebimento dos originais: 30/10/2020

Aceitação para publicação: 23/12/2020

\author{
Ludmilla Resende de oliveira \\ Universidade Federal de Minas Gerais Graduanda de licenciatura em História - CNPQ \\ E-mail: ludbortolini@gmail.com
}

\section{RESUMO}

Podemos dizer que a vida moderna atual só foi possível pelo brilhantismo das invenções de um grande homem: Nikola Tesla. Homem que rompeu a barreira e provou ser possível enviar eletricidade sem fio. Foi o visionário do século passado, estava um século a frente de seu tempo. E por quê devemos tanto a ele? Ele foi pai do rádio, antecipou a nível mundial a comunicação sem fio, o radar, a luz fluorescente, a bobina, o motor elétrico, a ignição elétrica, o carro elétrico, a energia sustentável, inventou a corrente alternada que com um simples interruptor nos leva energia a ponta dos dedos, a wirelles, o controle remoto, foi ele quem abriu as portas para todas as comodidades modernas elétricas como a Tv, microondas, geladeira, computador e muitos eletrodomésticos e eletrônicos e talvez precursor da invenção do raio-x! Tesla é simplesmente o responsável por todo o mundo moderno e há 100 anos Tesla já estava pronto com suas ideias.Tesla com seus projetos foi pioneiro, adiantou o progresso da ciência. E porque um cientista como este continua desconhecido de muitos? Porque o mundo que ele ajudou a construir o esqueceu completamente? Nós utilizamos os frutos do legado de Tesla, um dos inventores mais importantes da história da humanidade e responsável pelo século XX. De fato, o futuro pertence a ele.

Palavras-chave: Nikola Tesla, História da Ciência, Modernidade.

\begin{abstract}
We can say that modern life now was only possible by the brilliance of invention of a great man: Nikola Tesla. Man who broke the barrier and proved unable to send electricity wirelessly. It was the visionary of the last century was a century ahead of his time. And why should so much to him? He was the father of radio, he anticipated worldwide wireless communications, radar, fluorescent lights, coil, electric motor, electric ignition, electric cars, sustainable energy, invented the alternating current with a simple switch energy leads us to the fingertips, the handheld wireless, remote control, it was he who opened the door to all modern facilities like electric TV, microwave, refrigerator, computer and many appliances and electronics and perhaps a precursor of the invention of x-ray ! Tesla is simply responsible for the entire modern world and 100 years ago Tesla was ready with his ideias. Tesla was a pioneer with his projects, advancing the progress of science. And as a scientist as this remains unknown to many? Because the world he helped to build has completely forgotten? We use the fruits of the legacy of Tesla, one of the most important inventors in human history and responsible for the twentieth century. In fact, the future belongs to him.
\end{abstract}

Keywords: Nikola Tesla, History of Science, Modernity. 


\section{INTRODUÇÃO}

Nikola Tesla foi um grande engenheiro cientista conhecido até meados do século passado. Estranhamente seu nome foi esquecido e o trabalho de fazê-lo sobreviver através de estudos e pesquisas vem ganhando espaço atualmente na academia. Ele foi realmente o verdadeiro, pode-se dizer, profeta desconhecido da era eletrônica, sem o qual o rádio, a ignição elétrica de automóveis, o computador, o microondas, o telefone, a corrente alternada na tomada, robô, televisão, todos estes equipamentos seriam impossíveis. Mas apesar do brilhantismo de sua mente e de seu trabalho, a vida deste homem desapareceu do acesso ao público. Nikola Tesla foi um cientista espetacular e excêntrico. Seu nome faz sobreviver e prolongar os dias de Thomas Edson. Há admiradores que afirmam ser em Tesla e Faraday os maiores descobridores elétricos dos tempos modernos. John $\mathrm{O}^{\prime}$ Neill $^{11}$, autor da biografia de Tesla, afirma que não existiu homem melhor neste mundo. Este autor descarta os argumentos jornalísticos, e descreve Tesla como um "super-homem", como um dos maiores gênios que o mundo já teve. Ele dá créditos não só a invenção do gerador polifásico de corrente alternada e ao motor de indução de Tesla, que na verdade são instrumentos que os cientistas aclamam como a base da energia elétrica da nossa época. ${ }^{2}$ A descoberta de princípios básicos do rádio, radar, sonda eletrônica, quem sabe dos raios-x, da luz fluorescente, microscopia eletrônica, bomba de foguete e outros como a descoberta de raios cósmicos, foram inspirados pelas descobertas básicas de Tesla.

\section{DESENVOLVIMENTO}

Ele nasceu em 1856 na atual Croácia, antigo Império Austro-Húngaro. Publicou mais de 100 patentes, principalmente nos EUA, disponíveis no site USPTO - United States Patent Tradmark Office - escritório de patentes reconhecidas pelos EUA. Tesla foi aclamado como gênio pois inventou dínamos, transformadores, motor elétrico, bobinas de indução, condensadores, lâmpadas incandescentes. Eletricidade sem fio espalhada por todo o planeta Terra, raios mortais, máquina de terremotos, controle remoto e energia verde, são itens provenientes da mente fértil deste gênio que eletrizou o mundo. Ele pode ser considerado um dos heróis americanos, ele foi um dos inventores mais importantes da história da humanidade e o responsável pelo século XX. Pensar que ele teria uma visão diferente de como seria o mundo no futuro, é um caminho para saber mais sobre este homem singular. Hoje tem-se o mundo de eletricidade ao dispor, energia que move as necessidades, e que está ao alcance da tomada mais próxima. E segundo a lenda, o homem que fez possível isso tudo

\footnotetext{
${ }^{1}$ O' NEIL, John Jacob. Prodigal Genius: The Life of Nikola Tesla.

2 TIME, 20 de julho de 1931.
} 
acontecer, nasceu à meia noite, durante uma tempestade (elétrica!) de raios. Talvez este também seja mais um motivo da associação feita entre Tesla a raios e trovões.

O desenvolvimento progressivo do homem é extremamente dependente da invenção, que é o produto mais importante de um cérebro criativo. Tesla considerado um gênio extraordinário da eletricidade, estudou na juventude eletrodinâmica e era mesmo assim descrito como uma pessoa que possuía idéias "extravagantes". Por vezes, era considerado também um visionário por sua capacidade de visualizar aos mínimos detalhes dimensões exatas de novos dispositivos mecânicos provenientes de um cérebro inventivo. Ele tinha segurança ilimitada em sua inventividade visual e já não se incomodava a construir e raramente se preocupava em fazer anotações. Foi ele quem trabalhou durante muitas noites acordado, revolucionou máquinas de transmissão de energia e sem dúvida contribuiu mais do que qualquer outro homem para a ciência elétrica. De acordo com $\mathrm{O}^{\prime}$ Neill, Tesla criou mais de 200 invenções, mas ele rejeitou a maioria delas considerando-as como coisas pequenas e não as desenvolveu, deixando para que outros depois pirateassem seu trabalho. Tesla concentravase em projetos maiores, e o mais grandioso deles foi o sistema de transmissão de energia elétrica sem fios.

Quando o assunto é transformar noite em dia, pense em Nikola Tesla. Sem dúvidas, muitos aspectos da vida moderna, do dia-a-dia foram diretamente influenciados, pensados ou criados por ele. Por exemplo sua corrente alternada ou sistema AC que abriu as portas para todas as comodidades elétricas modernas: tv, torradeira, microondas, geladeira, computador e muitos outros eletrodomésticos e eletrônicos que estão dentro dos lares. O uso da corrente alternada deveria, particularmente, fazer sobreviver o nome do engenheiro elétrico que fez os aparelhos elétricos hoje possíveis de serem ligados e de funcionarem, afinal a transmissão universal e distribuição de eletricidade teve origem na sua mente singular, pois a indústria moderna e a energia elétrica de hoje são baseadas no seu sistema. O mundo seria muito mais escuro e triste sem a invenção de Tesla, as rodas das indústrias não funcionariam....

Os experimentos de Tesla, alguns já concluídos, foram financiados por patrocinadores como J. Pierpont Morgan, John Jacob Astor, John Hays Hammond, Thomas Fortune Ryan, Samuel Insull. E durante 20 anos de sua vida esteve no Hotel New Yorker, em Manhattan, sonhando com projetos maiores. Tesla teve grandes visões: em 1900 ele estava pronto para curar a tuberculose com a oscilação da eletricidade; em 1909 prometeu motores capazes de conduzir transatlânticos a 50 nós; em 1911 dirigíveis sem hélices a prova de tempestades; em 1924 planejava transmitir energia através do rádio, em 1927 planejava aproveitar o mar, em 1931 fazeria todos os combustíveis supérfluos utilizando a energia cósmica. E ainda, anunciou uma combinação de quatro invenções que fazeriam a 
guerra impensável. Este trabalho mostra que as idéias de Tesla, se naquele tempo já eram avançadas, continuam ainda sendo tão avançadas quanto para os dias atuais.

A carreira de Tesla teve início quando se tornou engenheiro elétrico em 1881 em Budapeste numa empresa de telefonia. O gerador de energia padrão do mundo foi esboçado na areia de uma praça, quando Tesla o pensou pela primeira vez, que é o motor elétrico de indução. Ele é usado em tudo, de eletrodomésticos a carros híbridos e fábricas industriais. Percebemos que as mesmas ideias que Nikola Tesla tinha há mais de um século ainda são usadas atualmente. Os motores de indução hoje ainda são exatamente aos de Nikola Tesla quando fez o primeiro protótipo. Em 1884, aos 28 anos, Tesla se mudou para os Estados Unidos, com pouco dinheiro e uma carta de recomendação de seu patrão para Thomas Edson. O texto da carta muito simples: "Conheço dois grandes homens, você é um deles e este jovem é o outro". Edson contratou o engenheiro e uma de suas tarefas era redesenhar geradores elétricos da empresa por 50 mil dólares extras. Depois de criar umas séries de patentes lucrativas, Tesla pediu a Edson o bônus prometido pelos geradores, e Edson respondeu dizendo que Tesla não conhecia o senso de humor americano e não o pagou. Tesla então, chateado, se demitiu. A partir de então teve início uma longa rixa entre os dois: a guerra das correntes. Enquanto lutava para sobreviver e levantar capital para novas invenções, Tesla ficava horrorizado com a rede de fios elétricos da cidade. O sistema era de cabos de fio pendurados sobre as cabeças e nalgumas áreas não dava para ver o sol. O sistema considerado eficiente na ápoca era a corrente direta, ou sistema DC, ou corrente contínua CC. E era Edson o grande investidor deste tipo de energia. Mas Tesla sabia que havia um jeito melhor e se dedicou a inventar um novo sistema que se tornou padrão mundial: a corrente alternada ou AC. A diferença entre estes dois tipos de corrente é na forma como os elétrons fluem. Porém, com a corrente CC os elétrons encontram resistência nos cabos e têm dificuldade em viajar longas distâncias e a energia se perde no cabo. A cada quilômetro Edson teria de colocar uma casa de força entre as estações para manter a voltagem estável ao longo da rede de energia. Em 1887, Tesla entrou com sete patentes americanas no sistema mais eficiente e menos dispendioso que é a corrente alternada, que poderia ser transmitida a centenas de quilômetros a mais que a corrente contínua, apenas alternando os pólos da corrente. O empresario G. Westhinghouse achava que as invenções de Tesla poderiam ser chave da transmissão de energia a longas distâncias, comprou as patentes de Tesla por 60 mil dólares e um pacote de ações da empresa Westhinghouse. Em 1891 Tesla se torna cidadão americano e neste mesmo ano teve início declaradamente à guerra de correntes. Edson lançou uma campanha propagandista que mostrava os perigos da corrente alternada. Para o público, Edson dizia que eram feitas experiências terríveis e que animais eram eletrocutados com corrente alternada. Edson ainda conseguiu convencer o Estado a utilizar na cadeira elétrica na primeira pena de morte a corrente alternada em 1892. Ninguém gostaria de ter uma corrente como esta dentro 
de casa, seria um perigo para os lares americanos. Em 1893, apesar da má publicidade, Tesla e a empresa Westhinghouse venceram a licitação para a Feira Mundial de Chicago, a primeira feira de eletricidade do mundo. Em primeiro de maio de 1893 o presidente pressionou o botão e mais de 200 mil lâmpadas incandescentes de Tesla iluminaram a feira. Foi um sucesso monumental que anunciou a era da iluminação elétrica moderna. Tesla foi o mentor intelectual que tornou a feira possível e deixou seu nome conhecido no mundo todo depois disso. Tesla acreditava que a CA seria a corrente do futuro e como prova tentaria tirar proveito das maiores maravilhas da natureza. A Westhinghouse ficou no vermelho depois da guerra das correntes, e num grande gesto para manter a empresa sem dívidas, Nikola Tesla encerrou seu contrato alegando que trabalhava em outras invenções.

Milhões de pessoas são testemunhas do poder das cataratas de Niágara. Mais de três milhões de litros de água são jogados por segundo, o que produziria energia suficiente para gerar 2,4 milhões de kilowatts de eletricidade. Nesse sentido, as cataratas forneceriam a energia para metade da cidade de Las Vegas apenas numa noite. Muitos, há tempos, imaginaram formas de tirar proveito das quedas d'água e do seu poder. Em 1893, depois do sucesso de Tesla ao acender a feira mundial de energia em Chicago, a comissão das cataratas o premiou com um contrato para utilização das águas para gerar corrente alternada, pois como dito, a energia CA evitava a construção de uma estação retransmissora a cada quilômetro. Assim, Tesla projetou um complexo sistema de geradores e motores para a produção de energia CA. Em 1896 a primeira estação hidroelétrica CA a longa distância foi inaugurada e Buffalo foi a primeira cidade a ser contemplada. Hoje novas estações substituem as estruturas de Tesla, os prédios de um dos locais históricos mais importantes do mundo moderno foram abandonados. E quanto ao homem que criou tudo isso, apenas uma estátua isolada celebra a incrível descoberta. Quantas pessoas passam em frente à estátua de Tesla e não fazem a mínima ideia de quem foi ele e o que fez para o mundo moderno? Hoje o mundo é iluminado graças à tecnologia CA de Tesla, que venceu a batalha contra Edson tendo um preço muito alto. E em 1912, recusou o prêmio Nobel que seria partilhado com Thomas Edson. Tesla refere-se a Thomas Edson da seguinte maneira:

"If Edison had a needle to find in a haystack, he would proceed at once with the diligence of the bee to examine straw after straw until he found the object of his search... I was a sorry witness of such doings, knowing that a little theory and calculation would have saved him ninety per cent of his labor. ${ }^{3}$,

\footnotetext{
${ }^{3}$ Nikola Tesla, New York Times, October 19, 1931. "Se Edison tinha uma agulha para encontrar em um palheiro, ele iria continuar de uma vez com a diligência das abelhas depois de examinar palha a palha até que encontrasse o objeto de sua busca ... Eu era uma testemunha lamentável de tais atos, sabendo que um pouco de teoria e cálculo teria o salvado noventa por cento do seu trabalho."
} 
Tesla neste fragmento refere-se a Edson, como aquele indivíduo que não estava interessando em cálculos, fórmulas e teorias. Mas sim como aquele que buscava já encontrar o trabalho pronto, já desenvolvido por outra pessoa que pensasse em seu lugar.

Tesla fez pesquisas com eletricidade de alta tensão, com a comunicação sem fio, radar, mísseis guiados, rádio, aeronaves, trabalhou em cima de um dispositivo em que ele acreditaria fazer a guerra impraticável, podendo mudar o curso da história. Tesla escrevia imaginando a vida 100 anos após o tempo presente, fazia previsões. Ele antecipou vários acontecimentos importantes e não seria sem certeza tentar prever a vida provável no século XXI. Os princípios sobre transmissão e recepção do nosso sistema de hoje, mostram claramente que Tesla também foi o pai da wirelles. Já é conhecido algo que ele procurava: a transmissão sem fio capaz de ser transmitida a todo o mundo, que foi citada inúmeras vezes. A chave para entender essa ideia singular é uma peculiar e poderosa invenção que patenteou em 1891: a bobina de Tesla, assim por ele batizada. Nada parecido havia sido feito antes, a bobina de Tesla é como se fosse uma bomba elétrica gigante. A bobina de Tesla eleva a voltagem de 120 para mais de 500 mil volts. A exemplo de quando os bombeiros encaixam a mangueira no hidrante e utilizam o bico para lançar água a grandes distâncias, a bobina de Tesla faz a mesma coisa, porém com a eletricidade. Ao utilizar uma enorme bobina de Tesla, o inventor pretendia encher a Terra e atmosfera de energia elétrica. Ele acreditava poder usar a terra como condutor natural de eletricidade e enviar energia para todos os cantos do mundo. Em resumo, a terra agiria como uma gigantesca tomada elétrica. A fim de provar tal teoria considerada maluca por muitos, Tesla se mudou da cidade de Nova York e em 1893 iniciou esperimentos com energia sem fio nas campinas do estado do Colorado. Tesla construiu um laboratório e uma torre de 25 metros de altura, que no seu interior ficava uma bobina de Tesla. A população de Colorado se preocupava com as experiências de Tesla utilizando a eletricidade, pois achava que Tesla executava uma obra divina. Conectada a rede local de Colorado Springs, a bobina de Tesla produzia mais de 12 milhões de volts. Tesla costumava demonstrar o conceito sem fio acendendo uma lâmpada fluorescente segurando-a nas maõs, pois com a máquina ligada o laboratório ficava cheio de eletricidade de alta voltagem. A bobina de Tesla produz energia elétrica sem ferir ao homem, similar a maneira como as torres de transmissão emitem ondas de rádio. O que se vê dentro do laboratório é eletricidade voando pelo ar, saindo da bobina até a lâmpada. Essa é a essência da ideia original de Tesla. Ele queria transmitir energia globalmente e as pessoas apenas precisariam recebê-la e usá-la. Tesla afirmou que as experiências em Colorado foram um sucesso, e que conseguiu fazer a transmissão de energia acendendo lâmpadas a 1,5 km de distância.

Em 1898 ele criou o controle remoto ao mostrar um barco de ferro controlado por ondas de rádio. Os princípios do controle remoto de Tesla são encontrados hoje em itens que vão da televisão a naves militares não tripuladas usadas em reconhecimento de campo, satélites operados no espaço. 
Embora muitas invenções de Tesla sejam úteis para a sociedade, suas ideias visionárias percorreram uma estrada escura gerando medo. Em 1917, Tesla propôs que ondas de rádio se refletissem em um objeto para determinar sua posição e velocidade. Isso aconteceu 17 anos antes da invenção do radar. Em 1934, Tesla criou um raio mortal. A ideia era explodir raios concentrados de particulas carregados com milhões de volts de eletricidade, o que poderia abater frotas de naves inimigas a uma distância de mais de 300 quilômetros. Com esta ideia Tesla aterrorizou as pessoas, inclusive o nome contribuia para apavorizar: raio mortal. O raio da morte é um velho conhecido para os cientistas. Depois da nave interplanetária é provavelmente a invenção mais popular da pseudo-ficção científica.

$\mathrm{Na}$ biografia que deixa de presente ao mundo, além de suas patentes, invenções e artigos escritos, ele esclarece os flashes luminosos que acostumava ter em alguns momentos de sua vida. E foi justamente em um desses momentos que pode visualizar e desenhar com um graveto na área o motor de indução quando ainda era jovem. Tesla tinha um desenvolvimento mental extraordinário e a consequência disto são os seus trabalhos audazes e inovadores, resultados do seu espírito de invenção. E com isso desenvolveu uma predileção ao preferir o pensamento para realizar as suas obras. Tesla teve um estado mental de felicidade ao poder conceber máquinas através do seu pensamento, suas ideias vinham em fluxo ininterrupto, vinham como relâmpagos, era capaz de imaginar os motores já funcionando, possuía uma mente fértil e disciplinada. Ele começava o seu trabalho as 3 da manhã e prosseguia até as 11 da noite, sábados, domingos e feriados. Sem dias de exceção. Tesla ficou consternado ao saber que Voltaire escrevia suas quase cem obras enquanto bebia 72 xícaras de café preto por dia...

Tesla, em sua autobiografia, diz que sua visão e audição sempre foram extraordinárias, podia discernir objetos claramente a uma certa distância quando outros não conseguiam ver nenhum traço do mesmo. Ouvia rumores do que acontecia nas noites e salvava vidas de um incêndio. Tinha a capacidade de ouvir trovões a 550 mil milhas e ouvir uma mosca posar sobre a mesa e médicos daquela época diziam que Tesla era incurável. E por mais que não se possa acreditar, estas "qualidades" transformaram Tesla em um homem de força extraordinária e tenaz, capaz de trabalhar mais de 38 anos quase sem interrupção. E teve muitas vezes que justificar para a imprensa que seu trabalho é autêntico. Seu trabalho era diferenciado e singular fazendo com que as pessoas desacreditassem nas suas propostas vendo o como visionário, bruxo, um homem profético. As pessoas na verdade não acreditavam nas suas ideias e nas suas propostas arrojadas, viam como impossíveis de serem criadas, como uma ilusão ou utopia. Para Tesla as invenções não estão esgotadas, o que se dá é o oposto e ele trabalhou muito para criar um mundo melhor.

Tesla acreditava ter rompido uma barreira e provado que podia enviar eletricidade sem fio, porém era necessário levantar dinheiro para construir uma bobina maior. Tesla voltou à costa oeste e 
o nome da rua marca o lugar do que é hoje um lugar abandonado. Em 1901, com base nas experiências feitas em Colorado, Tesla deu início à construção de sua visionária rede sem fio de energia o qual ele chamava de Wirdencliffe, local composto de um laboratório e de uma estação de energia que ao lado ficava uma torre de 57 metros de altura, em que a energia da estação era enviada para a bobina que ficava na torre, e embaixo desta, Tesla enterrou barras de 35 metros para transmitir a voltagem no solo. Este seria o primeiro de muitos transmissores em um sistema que contemplaria o mundo todo com a energia sem fio. A grande quantidade de eletricidade necessária viria de grandiosos projetos hidroelétricos.

Muitos achavam que Tesla era um louco, isso porque as pessoas não enxergavam como ele via e como via também o futuro. Ele, simplesmente conseguia imaginar coisas que outras pessoas não eram capazes, por isso ele foi considerado um visionário. Mas mesmo os visionários precisam de dinheiro. A fim de convercer o empresário J. P. Morgan a investir 150 mil dólares na construção de Wirdencliffe, Tesla prometeu que a torre renderia milhões na transmissão de mensagens, músicas, fotografias, notícias para qualquer parte do mundo. Foi em Wirdencliffe que Tesla ficou por mais de quatro anos tentando desenvolver o conceito sem fio, seus sonhos estavam vivos e o que ele mais desejava era ter um futuro de muita glória. Em 12 de dezembro de 1901, enquanto Tesla trabalhava na rede de energia, Guglielmo Marconi passou a frente e transmitiu com sucesso um sinal de rádio através do Atlântico. O feito de Marconi era algo inédito, mas na verdade, ele utilizou 17 patentes para conseguir sua proeza. Além de Tesla nunca ter sido considerado o pai do rádio ${ }^{4}$, a transmissão de Marconi selou o destino de Wirdencliffe. Morgan não se interessava mais em bancar Tesla, se Marconi já havia conseguido o que ele buscava. Entretanto, o plano de Tesla era muito maior do que Morgan pensava. Tesla via uma razão maior para continuar com o seu trabalho, mas este não era o plano de Morgan. Em 1905 o projeto foi então abandonado e posteriormente destruído.

Além das descobertas de eletricidade em Colorado, Tesla declarou que recebia mensagens do espaço. O que fez de Tesla um homem da publicidade em Nova York posto que havia se comunicado com Marte ou marcianos. As ideias de Tesla, interessantemente, são as mesmas que são usadas hoje para enviar mensagens para o espaço, como as ondas de rádio enviadas ao espaço para diagnosticar a existência de alguém naquele lugar. Com isso, as pessoas da sua época achavam-no um louco, diziam que Tesla profetizava, pensavam que ele era um cientista maluco, que poderia perder o controle e destruir o mundo, quando na verdade ele era apenas um homem a frente de seu tempo e tinha a intenção de melhorar a vida da humanidade.

\footnotetext{
${ }^{4}$ Em 20 de junho de 1943 a Suprema Corte dos Estados Unidos revogou a si mesma e garantiu a Tesla e não a Marconi a patente da invenção do rádio.
} 
Tesla publicou diversos trabalhos em revistas científicas como Scientific American, revista esta que lhe dava muita credibilidade, Electrical Experimenter, Astounding Scientific, Electrical Word and Engineer, Manufacture's Record, proferiu palestras na New York Academy of Sciences, Modern Mechanix and Inventions, foi indicado ao prêmio Nobel e muitos artigos foram escritos por terceiros sobre Tesla e seus inventos. Os estudos de Nikola Tesla hoje fazem parte de uma coleção de artigos científicos e outros trabalhos no campo da engenharia elétrica e inclusive da História. Dentre os 57 escritos, cita-se, a título de exemplo, A New System of Alternate Current Motors and Transformers ${ }^{5}$, Phenomena of Alternating Currents of Very High Frequency ${ }^{6}$, Experiments with Alternate Currents of Very High Frequency and Their Application to Methods of Artificial Illumination ${ }^{7}$, High Frequency Oscillators for Electro-therapeutic and Other Purposes ${ }^{8}$, Talking With Planets ${ }^{9}$,The Transmission of Electrical Energy Without Wires ${ }^{10}$, Electric Autos ${ }^{11}$, Tesla's Wireless Torpedo ${ }^{12}$, The Future of the Wireless Art ${ }^{13}$, The Wonder World To Be Created By Electricity ${ }^{14}$, Wonders of the Future ${ }^{15}$, Electric Drive for Battle Ships ${ }^{16}$, World System of Wireless Transmission of Energy ${ }^{17}$, Our Future Motive Power $^{18}$, The Eternal Source of Energy of the Universe, Origin and Intensity of Cosmic Rays ${ }^{19}$, Tesla Invents Peace Ray ${ }^{20}$, AMachine to End $\mathrm{War}^{21}$.Tesla teve laboratórios onde fazia seus experimentos em Colorado, Long Island, Nova York. Abriu a sua própria companhia Tesla Electric Ligth \& Manufacturing. Existem vários livros norte-americanos publicados, uma vasta e nova bibliografia sobre o gênio da modernidade.

Tesla tinha um laboratório em Colorado e em Long Island, onde, dizia o próprio inventor que a questão da potência da transmissão por fio para ele estava tão bem conhecida, a tal ponto constituída que ele poderia desenvolver seu projeto de transmitir uma potência de 100 mil volts sem utilizar fios com uma perda mínima de $5 \%$ da transmissão. E o preço para as instalações seria menor que as do telegrafo sem fio existente. E numa distância de 10 mil milhas ou de uma milha o efeito não seria

\footnotetext{
${ }^{5}$ AIEE Address, May 16, 1888.

${ }^{6}$ Electrical World, Feb. 21, 1891.

${ }^{7}$ AIEE, Columbia College, N.Y., May 20, 1891.

${ }^{8}$ Electrical Engineer, November 17, 1898.

${ }^{9}$ Collier's Weekly, February 9, 1901.

${ }^{10}$ Electrical World, March 5, 1904.

${ }^{11}$ Manufacturers' Record, December 29, 1904.

${ }^{12}$ New York Times, March 19, 1907.

${ }^{13}$ Wireless Telegraphy \& Telephony, Van Nostrand, 1908.

${ }^{14}$ Manufacturer's Record, September 9, 1915.

${ }^{15}$ Collier's Weekly, December 2, 1916.

${ }^{16}$ New York Herald, February 25, 1917.

${ }^{17}$ Telegraph and Telegraph Age, October 16, 1927.

${ }^{18}$ Everyday Science and Mechanics, December 1931

${ }^{19}$ New York, October 13, 1932.

${ }^{20}$ New York Sun, July 10, 1934.

${ }^{21}$ Liberty, February 1937.
} 
diferente e podia ser transmitido através do ar, do subsolo ou do chão. O laboratório construído por Tesla, de certa forma, foi problemático. Automóveis, locomotivas, navios transoceânicos, aviões, dirigíveis, todos teriam seu equipamento receptor de energia de correntes de indução de alta freqüência extraído de um "cobertor do globo" - globe-blanket. E este cobertor de correntes não seria prejudicial à saúde, visto que os amigos de Nikola Tesla o viram, assim como consta numa fotografia sua, na qual ele ainda lê um livro tranquilamente durante o fenômeno de emissão de faíscas elétricas em seu laboratório. Sua torre elétrica em Colorado produziu um potencial de 135 milhões de volts, número jamais atingido e alegou acender sem fios 200 lâmpadas incandescentes a 26 milhas de distância. Para Nikola Tesla, o mundo é uma casa de energia. Durante 40 anos ele raciocinou, calculou e argumentou que a Terra teria uma ressonância elétrica definitiva. O que ele precisava fazer para ter a energia ilimitada em seu comando sem a necessidade de cabos de transmissão seria gerar eletricidade em sintonia com a Terra. A inconveniência seria a despesa com a instalação e poderia não haver controle financeiro da eletricidade e a energia das casas na Terra seriam obrigadas a gerar o mesmo tipo de corrente. John Pierpont Morgan acreditava na possibilidade de transmissão de energia sem fio. Ele não era contrário ao controle da energia mundial e das comunicações. Morgan ofereceu a Tesla grande quantia de dinheiro para o experimento em Colorado, em 1899, Tesla construiu uma enorme bobina na qual gerou e enviou ondas sem fio. Neste mesmo ano, Marconi estabelecia comunicação sem fio entra a França e a Inglaterra. Tesla, então, reivindicou prioridade, afinal ele reconhecia seu sistema, seis anos antes, em 1893, mas o caminho das ondas de Tesla era através da Terra e não do ar como as ondas Hertzianas. A torre de 187 metros de altura foi a grande divulgação da energia sem fio. Morgan faleceu em 1913 e Tesla não pode mais continuar, abandonando a torre que foi destruída e 1917.A descoberta de Tesla de que a terra se comportava como um ser vivo de vibrações elétricas fez com que ele absorvesse um inquérito interessante sobre seus fenómenos e ele acreditava que chegaria nalguma grande revelação. O planeta se comportava como um enorme condutor capaz de transmitir energia. E ficou claro para Tesla que era possível enviar mensagens telegráficas a qualquer distância, sem fio! E o mundo para Tesla seria transformado. Ele acredita que esta mudança estava por vir. Para ele seria eficiente iluminar as massas e regiões menos acessíveis, adicionando segurança, conforto e conveniência e mantendo as relações pacíficas. Colocar em prática este sistema seria alocar em várias partes do globo um dispositivo de carregamento elétrico capaz de transmitir sinais aos confins da Terra. Em 1887, Tesla fez experiências 
com radiação de raios-X. Isso foi oito anos antes de Roentgen comentar sua própria descoberta dos raios-X, o que lhe rendeu o prêmio Nobel de física. ${ }^{22}$

Com sua mente procriadora e inventiva o que Tesla faz é tentar encaixar o uso da energia elétrica nalgum sistema e gerar benefícios. As suas perspectivas para o futuro são ilimitadas. No início do século XX as incríveis realizações de Tesla foram reconhecidas, mas ele morreu em 1943 num quarto apertado do hotel New York sem posses e sozinho enquanto via o mundo em que ajudou a criar esquecê-lo completamente. Aos 86 anos, depois da morte de Tesla, o governo americano confiscou suas anotações. Houve uma grande preocupação depois da morte do inventor, quanto às anotações científicas. A Segunda Guerra acontecia e havia o mito de que os nazistas poderiam pegar seus papéis. O governo americano alega que depois de examinar os papéis eles foram liberados em 1952 e mais tarde mandados para Belgrado na Ioguslávia, onde estariam até hoje no museu Nikola Tesla. Mas muitos acreditam que alguns papéis estão desaparecidos. E o que teria nestes papéis perdidos? Existe um grande mistério de quem pegou as anotações de Tesla, e será que não se terá o conhecimento do conteúdo destes documentos? Mas o que se sabe é que as ideias de Tesla estavam um século a frente de seu tempo. E há 100 anos Tesla já estava pronto. O FBI manteve um arquivo secreto sobre Tesla, mas que após a sua morte desapareceram misteriosamente. Como as ideias de Tesla eram consideradas assustadoras para a época, o Governo tomou seus pertences, mas alega que os documentos já foram devolvildos ao Museu de Tesla em Belgrado. Mas quais eram as ideias poderosas e tão assustadoras que ameaçavam a segurança nacional? Seria devaneio de um louco ou o trabalho de um gênio?

Os EUA consomem 200 milhões de barris de petróleo por dia e o valor da gasolina sobre constantemente. Cem anos atrás Tesla viu o futuro no combustível fóssil. O uso do petróleo, segundo Nikola Tesla, é de grande disperdício e faz a humanidade viver no limite, e atualmente a moderação vem sendo a causa de um mundo melhor para as próximas gerações. Tesla se assustava com a velocidade com que a sociedade queimava combustíveis não renováveis, como o carvão, o petróleo que começava a surgir. Ele previu uma era em que seria necessário recorrer a outras fontes de energia. Tesla previu o desenvolvimento do que hoje chamamos de energia renovável. Em 1901, ele patenteou um aparelho para utilização de energia radiante. A patente cita o sol bem como outras fontes de energia iradiada como os raios cósmicos. Nikola Tesla foi uma das primeiras pessoas a perceber que temos uma fonte quase inesgotável de energia vindo do espaço, que é o sol. Não seria de se apostar que Tesla hoje não ficaria surpreso ao ver os aparelhos de movidos a energia solar. Tesla também

\footnotetext{
${ }^{22}$ Esta ainda é uma informação que não se sabe ao certo. Apenas poucas fontes citam, mas não descrevem. Mas foi reafirmada pelo Documentário do History Channel.
} 
pensou na energia geotermal, ele escreveu um artigo para o New York Times falando de como aproveitar os recursos naturais da terra.

Hoje um fabricante de automóveis presta homenagem ao nome de Tesla e a sua genialidade adotando o nome do inventor. A Tesla Motors na Califórnia fabrica carros movidos a bateria que fazem de 0 a 60 km em menos de 4 segundos. Com uma versão do motor de indução de Tesla, o carro anda mais de $300 \mathrm{~km}$ sem uma gota de gasolina. Tesla foi pioneiro na iluminação, na feira apresentou a lâmpada fluorescente que não esquentava, diferente da lâmpada de Edson que aquecia, pois produzia mais calor ao invés de luz, precursor portanto das lâmpadas incandescentes da atualidade. Foi em 1893 que Tesla inventou esta lâmpada incandescente, que não esquentava, produzia luz através de um gás. O resultado é uma luz branca e fria e mais eficiente como se tem hoje. A lâmpada moderna funciona sobre o mesmo princípio que é o trabalho de Tesla.

\section{CONSIDERAÇÕES FINAIS}

A história pode ter negligenciado sua genialidade, mas hoje Tesla vem sendo redescoberto. E quem sabe poderão os cientistas de hoje descobrir os segredos que ele tanto confiava. Nikola Tesla fez do mundo moderno o que ele é hoje, embora tenha levado anos para que o mundo percebesse e agora ele passa a ter o seu merecido crédito. O legado de Tesla é o verdadeiro espírito criativo de inventor e não possuir limites para os conceitos.

O seu legado para o mundo e hoje podermos desfrutar dos meios eletrônicos por meio da eletricidade, de apenas um toque no interruptor ou na tomada. O que viria depois de os sonhos serem superados e o mundo surpreendido com o impossível? Muitos cientistas se questionam se Tesla teria dado certo, afinal a comunidade científica tem diferentes opiniões. A eletricidade sem fio estava fora de questão, não fazia sentido para alguns, mas seus defensores acreditam que a energia sem fio é possível. A ideia de que a energia sem fio pode ser transportada para o mundo todo é ainda uma ideia muito grande para se deixar passar. Mas por quê ainda, depois de um século da destruição de Wirdencliffe, as ideias de Tesla ainda são estudadas com tanta paixão pelos cientistas? Talves porque bem antes de Wirdencliffe Tesla já havia mudado o mundo.

Algumas das propostas de Tesla:

1) Transmitir cartas e encomendas através dos mares, utilizando um tubo submarino, resistente a pressão hidráulica. E seria construído em torno do Equador, fazendo viajar mil milhas por hora.

2) Tirar o poder da energia rotacional dos corpos terrestres.

3) Máquina para acabar com a guerra - raio da morte, conhecido nas ficções científicas. 
4) Transmissão de energia sem fio, desacreditada por muitos.

5) Descobrir o potencial elétrico da terra e estudar as suas flutuações.

6) As maravilhas que estariam por vir com a utilização da alta tensão, como a defesa contra incêndios, destruição de microrganismos, insetos, roedores pelo meio elétrico.

7) Segurança das embarcações no mar, instrumentos elétricos que evitarão as colisões no mar.

8) Dispensar nevoeiros pela força elétrica e raios de penetração.

9) Iluminar oceanos sem fios contribuindo para a segurança de bens e a vida no mar.

10) A eletroterapia teria um grande futuro, a partir das correntes de alta frequência. Esta forma de energia estaria disponível nas residências, uma das aplicações seria acabar com o banho diário e a limpeza seria feita instantaneamente, bastando ligar o corpo a uma fonte de correntes, que faria jogar fora a poeira e pequenas partículas aderidas a pele. Tal banho seco seria conveniente, economizaria tempo e traria benefícios terapêuticos.

11) Quanto a criminalidade, a prova elétrica seria decisiva, seria possível ver uma imagem formada no pensamento de uma pessoa em uma tela e isso se tornaria visível em qualquer lugar desejável.

12) Para a telefonia a transmissão de imagens - telefonar fotos - alcançaria seu sucesso.

13) A máquina de escrever elétrica operada pela voz humana.

14) Tesla escreve um ano após a Primeira Guerra Mundial, suas ideias encontram-se embebidas desta conjuntura internacional. Portanto prevê a construção de armas elétricas, como encouraçados e submarinos com antenas elétricas e magnéticas que seriam detectados no escuro, e o controle sem fio de máquinas automáticas a distância teria, segundo ele, papel importante numa guerra futura.

15) Uso da energia elétrica para propulsão de navios.

16) O carro elétrico.

17) A comunicação interplanetária.

Tesla, em sua autobiografia, diz acreditar ser um dos homens mais trabalhadores, e se o pensamento é para ele equivalente ao trabalho, ele tem se dedicado quase todas as suas horas de vigília. Segundo ele, todo esforço compulsório exige sacrifício da energia vital e ele, conclui, nunca pagou por este preço. Trabalhava, portanto, com gosto e devoção, prosperava em seus pensamentos, construindo a história da sua vida e determinando as circunstâncias e acontecimentos fundamentais da sua carreira. Ele tinha conhecimento do valor substancial dos pensamentos que cultivava e do seu legado para o mundo. Nikola Tesla pode ser considerado como um profeta desconhecido da era eletrônica, sem ele o rádio, a auto-ignição, o telefone, instrumentos que alteram a geração e 
transmissão da energia atual, como o rádio e a televisão, teriam sido impossíveis. Ainda existem espaços para a contribuição de Nikola Tesla, muitas pessoas acreditam que ele tinha um plano maior, talvez seja hora de voltar e investigar o que Tesla realmente procurava.

"Deixe que o futuro diga a verdade, que avalie cada um de acordo com o seu trabalho e realizações. $O$ presente pertence a eles, mas o futuro pelo qual eu sempre trabalhei pertence a mim".

Nikola Tesla 


\section{BIBLIOGRAFIA}

Science: Damn Good Man. In: TIME, July 25, 1927 Disponível em: http://www.time.com/time/magazine/article/0,9171,736807-1,00.html

Science: Superman of the Waldorf. In: TIME, Nov 27, 1944. Disponível em: http://www.time.com/time/magazine/article/0,9171,796925,00.html

Science: Tesla at 75. In: TIME, Jul 20, 1931. Disponível em: http://www.time.com/time/magazine/article/0,9171,742063,00.htmlCHENEY, argaret.Tesla: Man Out of Time. Touchstone; 1 edition, October 2, 2001.

TESLA, Nikola \& CHILDRESS, David H. The Fantastic Inventions of Nikola Tesla,1993.

TESLA, Nikola. Expirements with Alternating Currents. Gordon Press Publishers, 1986.

TESLA, Nikola. Nikola Tesla: Colorado Springs Notes 1899-1900. Gordon Press Publishers, 1986.

TESLA, Nikola. My Inventions: The Autobiography of Nikola Tesla. Hart Bothers Publishing. 1982.

O'NELL, John J. (John Joseph), 1889- Prodigal Genius: the Life of Nikola Tesla

Angriff Press, 1981. 